\title{
Sylwia Szykowna
}

https://orcid.org/0000-0002-4943-2539

(Gniezno)

\section{MIĘDZY ARCHIWUM A BAZĄ DANYCH \\ - O DOŚWIADCZENIU SZTUKI NOWYCH MEDIÓW}

\section{Abstract}

The essential objective of this paper is to examine the category of archive from the perspective of new media, which transform the model of linear historical discourse into a new one, whereby it assumes the form of a database, enabling novel modes of indexing reality.

\section{Key words}

archive, database, the archival turn, new media art, WRO Art Center, estetyka relacyjna, post-production 


\begin{abstract}
Ludzie tak naprawdę nie nauczyli się jak porządkować informacje oparte na czasie w nagraniach i bardzo dobrze, ponieważ to jest nowe. Nikt nie mówi że Encyklopedia Britanica jest nudna (...), ponieważ możesz przejść na dowolną stronę encyklopedii, do A lub B lub C lub M lub X, podczas gdy kiedy oglądasz kasetę wideo czy telewizję, musisz przejść A, B, C, D, E, F, G. Chociaż porównanie jest proste, różnica jest bardzo duża. (...) Dopóki informacje elektroniczne nie przezwyciężą problemu dostępu losowego.
\end{abstract}

Nam June Paik ${ }^{1}$

W 1963 roku Nam June Paik stworzył pracę „Random Access”, w której pocięta taśma magnetyczna pozwalała na losowe i zależne od odbiorcy odtwarzanie dźwięku. To działanie wyznacza zarówno początek sztuki medialnej, jak i zapowiedź tematyki bazodanowej żywo obecnej we współczesnej praktyce artystycznej ${ }^{2}$. W podejmowanych działaniach Paik rozwijał idee partycypacji, zmiany, indeterminizmu w sztuce, pragnął przekroczyć ograniczenia ówczesnych mediów analogowych takich jak telewizja czy wideo. Będąc pod silnym wpływem estetyki muzycznej Johna Cage'a i jego idei przestrzeni "demokratyzacji dźwięków” (democratization of sounds) ${ }^{3}$, badał otwarte formy muzyczne, w ramach których odbiorca stawał się aktywnym współtwórcą, próbując przezwyciężyć problem tytułowego dostępu losowego determinującego praktyki odbiorcze. Praca „Random Access” stawia jednocześnie nowe pytania dotyczące współczesnych praktyk wystawienniczych i konserwatorskich dzieł medialnych opartych na aktywnym współudziale odbiorców. Jak trafnie zauważa Hanna Barbara Hölling, duża część dzieł opartych na procesie funkcjonuje obecnie $\mathrm{w}$ ramach instytucji, muzeum na wzór swoistych reliktów sztuki, zazwyczaj zdezaktywowane, niedające się w żaden sposób uruchomić, stają się obiektami swoistego kultu, niczym religijne „relikwie często służące jako pomniki zmarłych świętych”. W niniejszym artykule postaram się zbadać relacje pomiędzy dziełami sztuki nowych mediów i archiwum rozumianym $\mathrm{z}$ jednej strony jako koncept kulturowy, z drugiej zaś jako fizycznie istniejąca przestrzeń magazynowania i przechowywania dzieł sztuki. Przyjrzę się zmianom w ramach samej kategorii archiwum, śledząc proces przejścia od materialnych systemów archiwizowania w stronę niematerialnych banków informacji, analizując zremediowaną wersję archiwum - bazę danych.

\footnotetext{
${ }^{1}$ Cyt za: Hölling, s. 84.

${ }^{2}$ Zob. Celiński 2013.

${ }^{3}$ Zob. The Art. Od Participation 2008, s. 98.

${ }^{4}$ Hölling 2017, s. 85.
} 


\section{BAZY DANYCH}

Charles Merewether we wstępie do redagowanego przez siebie tomu „The Archive” pisze, że

wzrost znaczenia archiwum za pomocą którego wiedza historyczna czy formy pamięci są gromadzone, przechowywane i odzyskiwane jest jedną z charakterystycznych cech nowoczesności ${ }^{5}$.

Szerszego kontekstu do prowadzonej refleksji dostarcza kategoria „zwrotu archiwalnego" (archival turn), który wpisuje się w całokształt przemian zachodzących w ostatnich dekadach w naukach humanistycznych, definiowanych za pomocą kategorii „zwrotu badawczego"'. W refleksji teoretycznej pojawiają się $\mathrm{w}$ związku $\mathrm{z}$ tym kolejne pojęcia próbujące uchwycić proces zmian w zakresie rozumienia i sposobów wykorzystania archiwów. Jacques Derrida mówił w tym kontekście o "gorączce archiwum” (Archive Fever), wewnętrznym impulsie, który określa ludzką egzystencję w jej dążeniu do „zapewnienia przyszłości zawsze zagrożonej skończonością"7. Hal Foster wprowadził pojęcie „impulsu archiwalnego” (an archival impulse), które odnosił do szeroko rozumianych praktyk artystycznych reprezentowanych przez współczesnych artystów, m.in. Thomasa Hirschhorna, Tacitę Dean i Sama Duranta, wykorzystujących krytyczny potencjał zjawiska archiwum w celu ustanawiania alternatywnych „kontr-pamięci”.

Komputer zasadniczo zmienił praktykę zarówno archiwizacji, jak i wyszukiwania danych, przekształcając całą terminologię archiwalną, w tym także samo pojęcie archiwum. Już w 1945 roku jego archiwizacyjny potencjal dostrzegł Vannevar Bush, który w tekście „As We May Think” kreował futurystyczną wizję komputera jako maszyny pamięci. Urządzenie Memex, przeznaczone do indywidualnego użytku, miało, w założeniu autora, być rodzajem prywatnej biblioteki czy magazynu książek, nagrań, zdjęć, różnego rodzaju materiałów, w większości utrwalonych na mikrofilmach. Wyzwaniem współczesności jest redefinicja sposobu myślenia o kulturowych archiwach w dobie współczesnych mediów sieciowych. Upowszechnienie się sieciowej technologii komputerowej $\mathrm{z}$ jej potencjałem magazynowania i transmisji danych,

\footnotetext{
${ }^{5}$ Merewether 2006, s. 10.

${ }^{6}$ Obok zwrotu lingwistycznego, w naukach humanistycznych dokonał się m.in. zwrot antropologiczny, interpretacyjny, kulturowy, pragmatyczny, performatywny, narratywistyczny, wizualny, przestrzenny. Zob. Zwroty badawcze w humanistyce konteksty poznawcze, kulturowe i społeczno-instytucjonalne, Kowalewski, Piasek 2010.

${ }^{7}$ Derrida 2006, s. 13.

${ }^{8}$ Foster 2004, 110.
} 
połączone ze zmianą paradygmatu komunikacyjnego związanego z przejściem od Web 1.0 do Web 2.0, spotęgowało i przyspieszyło zmiany w sposobie myślenia o kulturowych archiwach. Internet stał się rodzajem metabazy, rezerwuarem różnorodnych treści generowanych w różnych okresach, który charakteryzuje się nieograniczoną wręcz chłonnością i powszechną dostępnością, bazą która pomieści każdą ilość cyfrowo zakodowanych informacji, udostępnianych przez każdego i wszędzie. Dominujący do niedawna model linearnego dyskursu historycznego wypiera nowy przyjmujący właśnie postać bazy danych, dający nowe możliwości indeksowania rzeczywistości. Pojęcie baz danych w dużym stopniu pokrywa się z opisaną przez Wolfganga Ernsta ideą an-archiwum, którego w przeciwieństwie do tradycyjnego archiwum nie można ostatecznie uporządkować ani skatalogować, ponieważ jest dynamiczne, nieustannie wykorzystywane i stale rozszerzane. W tym sensie baza danych przyjmuje postać „archiwum w ruchu” (archive in motion), zdradzając swą niekompletność i otwartość raczej niż zastygnięcie przeszłości w czasie. W obliczu dokonujących się zmian technologicznych Ernst dostrzega przejście od kultury magazynowania do kultury transmisji, która pozwala tym lepiej zrozumieć współczesne postmedialne (re)praktyki artystyczne oparte na powtórzeniu, remiksie czy postprodukcji ${ }^{9}$. Kategoria baz danych wpisuje się w klimat decentralizacji współczesnej kultury. Środowisko baz danych sprzyja myśleniu o świecie i kulturze jako archiwum, zbiorze elementów, które można dowolnie wykorzystać, organizując i zarządzając dostępną nam informacją. Zdaniem Piotra Celińskiego

To reguły baz danych umożliwiły „kulturę uczestnictwa, kulturę użytkownika czy Web 2.0" (...). Myśleć bazodanowo znaczy uznać atomistyczną konstrukcję wszechświata, życia i kultury jako stan naturalny, w którym dokonują się nieustanne rekonstrukcje, $\mathrm{w}$ którym atomy/bity są $\mathrm{w}$ nieustannym ruchu poddane coraz to nowym zarządzeniom, przybierają nieustannie nowe kształty, i nauczyć się w nim żyć ${ }^{10}$.

Wszędobylskie archiwa są na tyle powszechne, że wtapiają się niepostrzeżenie w dzisiejszy pejzaż życia społecznego. Komputerowa baza danych, spełniająca współcześnie funkcję cyfrowego archiwum, jest dla Lva Manovicha

\footnotetext{
nowa symboliczna forma ery komputerowej, (...) nowym sposobem nadawania struktury naszemu doświadczaniu siebie i świata. Jeśli, jak powiada, po śmierci Boga (Nietzsche), upadku wielkich narracji oświecenia (Lyotard) i nadejściu sieci (Tim Berners-Lee) świat wydaje nam się nieskończonym i niezorganizowanym w żadną strukturę zbiorem obrazów, tekstów i innych danych, jedynym właściwym rozwiązaniem wydaje się traktowanie go w kategoriach bazy danych ${ }^{11}$.
}

\footnotetext{
${ }^{9}$ Zob. Ernst 2015.

${ }^{10}$ Celiński 2013, s. 130

${ }^{11}$ Manovich 2006, s. 334-335.
} 
W odróżnieniu od wcześniejszych analogowych form gromadzenia i katalogowania informacji, tj. biblioteki, muzeum, gabinetu osobliwości, ich zremediowana wersja oferuje niemożliwe wcześniej sposoby szybkiego wyszukiwania i filtrowania. Manovich utrzymuje, że w przeciwieństwie do przyczynowo-skutkowego uporządkowania narracji nielinearny układ bazy danych gwarantuje równoczesny dostęp do jej poszczególnych składników bez predeterminacji sposobu ich konfigurowania i doświadczania. Uważa, że baza danych prezentuje świat jako zbiór nieuporządkowanych elementów, narracja zaś, porządkując je, tworzy określone sekwencje znaczeń:

Większość obiektów nowych mediów nie opowiada żadnej historii; nie mają po-
czątku, ani końca; nie występuje w nich żaden rozwój, który tematycznie, formalnie
albo jeszcze inaczej zorganizowałby ich elementy w sekwencje. Są one zbiorami
indywidualnych części składowych, z których każda ma takie samo znaczenie jak
pozostałe ${ }^{12}$.

Z punktu widzenia odbiorczych doświadczeń bazy danych „wydają się zbiorami elementów, na których użytkownik może dokonywać operacji różnego rodzaju - oglądać, nawigować, wyszukiwać”13. Ich recepcja zasadniczo różni się tym samym od odbioru form narracyjnych, tj. czytania książek czy oglądania filmów. „Podobnie, jak w przypadku literackiej lub kinowej fabuły, pisze Manovich, planu architektonicznego i bazy danych - każde z nich stanowi inny model struktury świata” ${ }^{14}$. „Baza danych i narracja są zatem naturalnymi wrogami" 15 , odmiennymi modelami poznawczymi rywalizującymi ze sobą o prawo do nadania znaczenia światu. Stosunek bazy danych do narracji nie jest jednak tak jednoznaczny. Jak słusznie zauważa Grahame Weinbren, pionier kina interaktywnego, każde doświadczenie bazy danych jest przeżyciem pojedynczej drogi $\mathrm{w}$ „morzu historii” ${ }^{16}$. W świetle przemyśleń autora słynnej Sonaty (1991-1993) związek narracji i bazy danych ma zatem charakter relacyjny, a praktyka ich użycia pokazuje współzależność ich występowania. Komputerowe bazy danych urzeczywistniły marzenia Nam June Paika, wyrażone w przywołanej na początku pracy „Random Access”, przekraczając barierę losowego dostępu i otwierając nas na doświadczenie świata jako kolekcji, na którą składa się to, co było, jest i dopiero będzie udziałem przyszłych pokoleń.

${ }^{12}$ Ibidem, s. 333.

${ }^{13}$ Ibidem, s. 334

${ }^{14}$ Ibidem.

${ }^{15}$ Ibidem, 342

${ }^{16}$ Weinbren 2007. 


\section{ARCHIWA SZTUKI NOWYCH MEDIÓW}

„O czym zapominają archiwa?” - pyta w jednym ze swoich tekstów Luiza Nader, analizując archiwum duetu artystycznego KwieKulik przez lata, na własną rękę, gromadzącego materiały związane $\mathrm{z}$ awangardową praktyką artystyczną okresu PRL-u w myśl hasła: „trzeba ratować” ${ }^{17}$. Trzeba ratować od zapomnienia i oddać głos wykluczonym z dyskursu pamięci. Autorka zwraca uwagę na problematyczną z punktu widzenia historii sztuki nieobecność w szerszym dyskursie historycznym twórczości artystów pochodzących z Europy Środkowej i Wschodniej. Jednym z symptomów wspomnianego wykluczenia jest publikacja „Art Since 1900” z 2004 roku autorstwa Hala Fostera, Rosalind Krauss, Yve-Alaina Bois i Benjamina Buchloha, która zdaniem Piotra Piotrowskiego, „pomimo wielu zalet w ogóle nie podejmuje perspektywy krytycznej geografii ani geohistorii”"18. Opisana przez Luizę Nader sytuacja odnosi się ściśle do wprowadzonej przez Derridę koncepcji „gorączki archiwum", która $\mathrm{z}$ jednej strony dotyka praktyk pamięciowych związanych z kompulsywnym procesem zapamiętywania czy przypominania przeszłości, z drugiej zaś ujawnia mechanizm wymazywania, zapominania o tym, co do pamięci trafić nie może ${ }^{19}$. Kolejną $\mathrm{z}$ takich marginalizowanych opowieści jest historia sztuki nowych mediów, również przemilczana przez historyków sztuki i krytyków z kręgu pisma "October” we wspomnianej już publikacji, która dochodzi do głosu dzięki działalności instytucji, podmiotów, jednostek, budujących alternatywną względem artystycznego mainstreamu historię sztuki współczesnej. Świat sztuki nowych mediów ${ }^{20}$ nieustannie podważa hegemoniczność uniwersalnej historii sztuki, aktywizując opisane przez Fostera alternatywne kontr-pamięci. Archiwa sztuki nowych mediów przywołują zapomniane i rozproszone opowieści, odsłaniają to, co dotąd zakryte i nieobecne w uniwersalistycznym dyskursie historii sztuki. Wirtualna przestrzeń baz danych znajdujących się na różnorodnych platformach prezentacji sztuki nowych mediów (m.in. Database of Virtual Art powstałe z inicjatywy Olivera Graua, ArtBase w ramach Rhizome.org, netzspannung.org powstałe z inicjatywy Moniki Fleischmann i Wolfganga Straussa, Media Art Net powstałe z inicjatywy Dietera Danielsa i Rudolfa Frielinga ${ }^{21}$ czy stronach inter-

${ }^{17}$ Zob. Nader 2019.

${ }^{18}$ Ibidem

${ }^{19}$ Zob. Derrida 2006.

${ }^{20}$ Zob. Szykowna [w druku].

${ }^{21}$ Zob. Zawojski 2010, s. 223-246. 
netowych instytucji ${ }^{22}$ uzupełnia historyczno-artystyczne narracje, negocjując sensy i znaczenie w obrębie współczesnego świata sztuki. Przykładem dobrze ilustrującym opisane wyżej strategie przywoływania pamięci jest działalność wrocławskiego Centrum Sztuki Nowych Mediów WRO. Ta najważniejsza polska instytucja związana ze sztuką mediów,

\begin{abstract}
realizuje działania w szerokim zakresie, w autorskim modelu Laboratorium WRO, łącząc kompetencje od innowacyjnych, twórczych, przez naukowe i technologiczne, po edukacyjne i organizatorskie, eksperymentując z narzędziami i sposobami upowszechniania sztuki, tworząc własne oryginalne rozwiązania i opracowania wystaw, obiektów artystycznych, działań edukacyjnych, dokumentacji sztuki, i publikacji multimedialnych ${ }^{23}$.
\end{abstract}

Otwarte w 2008 roku Centrum Sztuki WRO posiada najobszerniejszą w Polsce i jedną z większych w Europie kolekcji prac medialnych artystów pochodzących z całego świata. Dzięki organizowanemu od 1989 roku Biennale ${ }^{24}$ archiwum WRO zawiera bogaty zbiór prac wideo, dokumentacji działań, instalacji, performansów, nagrań czy demonstracji prac interaktywnych. Podejmowane przez Centrum Sztuki WRO działania wpisują się w autorską koncepcję „aktywnego archiwum”, którego główną rolą jest, jak podkreśla Piotr Krajewski,

\begin{abstract}
transmisja treści historycznych i źródłowych, sprzyjająca tworzeniu w teraźniejszości świadomych i zaktualizowanych doświadczeń będących udziałem zarówno twórców, jak i odbiorców ${ }^{25}$.
\end{abstract}

Archiwum WRO to jednocześnie ogólnodostępna wielowymiarowa Czytelnia WRO znajdująca się w siedzibie Centrum przy ulicy Widok 7 we Wrocławiu, w której oprócz stanowisk dających możliwość zapoznania się z materiałami audiowizualnymi pochodzącymi $\mathrm{z}$ jego bogatych zbiorów można też zapoznać się z Biblioteką WRO, która gromadzi szereg unikatowych wydawnictw związanych $\mathrm{z}$ szeroko rozumianą współczesną praktyką artystyczną. Odrębną przestrzeń archiwalną stanowi także Atelier WRO, w którym znajduje się archiwum prac i pracownia digitalizacji, opracowująca

\footnotetext{
${ }^{22}$ Strony internetowe archiwów najważniejszych festiwali sztuki nowych mediów w Europie to m.in.: Prix Ars Electronica w Linzu (od 1979): <https://ars.electronica.art/error/de/archive/>, Transmediale w Berlinie (od 1988): <https://transmediale.de/archive >, WRO Media Art Biennale we Wrocławiu (od 1989): <http://wrocenter.pl/pl/archiwum-biennale-wro/>, DEAF Dutch Electronic Art Festival w Rotterdamie (od 1994): <http://v2.nl/archive $>$.

${ }^{23} \mathrm{O}$ WRO 2018.

${ }^{24}$ Od 1989 roku organizowano coroczny festiwal Wizualnych Realizacji Okołomuzycznych (w skrócie WRO), przemianowany w 1995 roku na Biennale Sztuki Mediów WRO i od 1993 roku odbywający się co dwa lata.

${ }^{25}$ Krajewski 2016, 1.
} 
i katalogująca gromadzone od lat materiały związane z historią sztuki medialnej, jak również wynajęta przestrzeń magazynowa zlokalizowana w Smardzowie niedaleko Wrocławia, w której gromadzone są archiwalia pochodzące z blisko 30-letniej historii festiwalu, w tym dzieła zapisane na różnych nośnikach danych (kasety VHS, betakamy, kasety jumatik, CD-ROMy) nagrania cyklu programów telewizyjnych „WRO taśmy mieszane” emitowanego przez Drugi Program Telewizji Polskiej do 2000 roku, druki, elementy architektury wystawowej czy sprzęt techniczny, wykorzystywany przy organizacji kolejnych edycji festiwalu. Zbiory magazynu doskonale obrazują zawrotne tempo zmian technologicznych zachodzących w sztuce nowych mediów. Bruce Sterling, w napisanym w 1995 roku artykule pod tytułem „The Dead Media Project. A Modest Proposal and a Public Appeal", pisał, że media cyfrowe umierają $\mathrm{w}$ tak szybkim tempie, że często nie jesteśmy nawet $\mathrm{w}$ stanie ustalić odpowiedniej terminologii dla ich scharakteryzowania ${ }^{26}$. Autor manifestu cyberpunkowego twierdzi wręcz, że możemy dzisiaj mówić o „cyfrowym rozpadzie" (digital decay), gdyż nowe media starzeją się znacznie szybciej niż starsze generacje mediów analogowych, a stosunek społeczeństw zachodnich do pojawiających się nowych technologii ma wymiar czysto komercyjny ${ }^{27}$.

Zmiany technologiczne czasami dotkliwie rozprawiły się z dziełami sztuki medialnej. Niektóre z dzieł net artu działają niepoprawnie bądź zniknęły bezpowrotnie, np. wybrane prace pionierki sztuki internetu Olii Lialiny, które z przyczyn technicznych trafiły do obszaru tzw. martwych mediów (dead media). Trudno przełożyć drobne subtelności, np. charakterystyczne dla dawnych systemów opóźnienia, związane z ograniczoną wydajnością ówczesnych procesorów komputerowych, trudno zrekonstruować nie tylko prace, ale też ich percepcję. Znaczący postęp w zakresie transferu danych, problem automatycznego update'owania programów, powodują trudności z odtworzeniem takich samych lub choć podobnych funkcji realizowanych przez pionierskie dzieła sztuki medialnej. Coraz częściej pojawia się w związku $\mathrm{z}$ tym refleksja dotycząca potrzeby wypracowania odpowiednich procedur konserwacji i ochrony dzieł opartych na procesie, w obliczu bardzo zmiennych formatów zapisu. Temat ten podejmują w swych badaniach Elżbieta Wysocka, omawiając zastosowaną metodę emulacji ${ }^{28} \mathrm{w}$ przypadku konserwacji

${ }^{26}$ Streling 2017a

${ }^{27}$ Sterling $2017 \mathrm{~b}$.

${ }^{28}$ „Emulacja (...) odnosi się do symulacji środowiska cyfrowego dla przedawnionych aplikacji. W przypadku dzieł software art i innych obiektów, których autentyzm wiąże się ze szczególnym językiem programowania i dla których kluczowe jest użytkowanie oryginalnego systemu operacyj- 
sieciowego projektu Olii Lialiny „Agatha Appears” z 1997 roku $^{29}$, jak również Hanna Barbara Hölling, analizując od strony konserwatorskiej twórczość Nam June Paika i proponując przejście od koncepcji konserwacji w stronę kontynuacji dzieł, uwzględniające „zmienność dzieł-procesów”30. Archiwa sztuki opartej na procesie muszą sprostać wyzwaniom, jakie niosą ze sobą szybki rozkład nośników czy gwałtowne zmiany dokonujące się w zakresie kontekstualizacji dzieła w konsekwencji prowadzące do dezaktualizacji i niekompatybilności gromadzonych w nich dzieł.

\section{DZIEŁO SZTUKI JAKO ARCHIWUM}

Charakterystyczne dla współczesnej praktyki artystycznej swoiste spoglądanie artystów w przeszłość jest przejawem szerszej tendencji żywego zainteresowania samą kategorią archiwum, która nie tylko definiuje pracę artysty, ale równocześnie organizuje wewnętrzną budowę dzieła i określa sposób jego funkcjonowania w szerszym obiegu sztuki. W tej nowej sytuacji dzieło sztuki staje się archiwum, akumulując w sobie doświadczenia przeszłości, teraźniejszości i przyszłości.

Andrzej Leśniak, przywołując słowa Dietera Roelstraetego, wskazuje na rosnący udział praktyk retrospektywnych w dzisiejszej działalności artystycznej:

Coraz częściej sztuka spogląda za siebie, jednocześnie na swą własną przeszłość (...), i na przeszłość w ogóle. Rosnąca liczba współczesnych praktyk artystycznych polega nie tylko na opowiadaniu, ale też na opowiadaniu o historii ${ }^{31}$.

W tej nowej sytuacji szczególnego zainteresowania praktykami retrospektywnymi zmienia się rola i status samego artysty, który staje się historykiem (Artist as Historian) $)^{32}$, archiwistą (Artist as Archiwist) ${ }^{33}$, semionautą ${ }^{34}$, kuratorem treści (Artist as Curator) ${ }^{35}$, dostawcą kontekstu (context provider) ${ }^{36}$,

nego lub oprogramowania i sprzętu, eksperymentalne metody, jak emulacja i wirtualizacja środowiska będą lepszym rozwiązaniem. (...) Proces emulacji nie skupia się na uruchamianiu oryginalnych plików w dawnym środowisku informatycznym, ale na takim wykorzystaniu współczesnego oprogramowania, by dzieło zadziałało we współczesnej sytuacji informatycznej”. Wysocka 2013, s. 408.

${ }^{29}$ Zob. ibidem.

${ }^{30}$ Zob. Hölling 2017. Zob. także: Hölling 2016b.

${ }^{31}$ Cyt za: Leśniak 2011, s. 102.

${ }^{32}$ Zob. Godfrey 2007, s. 142-143.

${ }^{33}$ Zob. Foster, 2004.

${ }^{34}$ Zob. Bourriaud 2002b, s. 14.

${ }^{35}$ Zob. Bourriaud 2002a.

${ }^{36}$ Zob. Lovejoy 2011. 
poruszającym się po meandrach tradycji, czyniąc z nawigacji kwintesencję swojej praktyki artystycznej. Dekodując i reinterpretując utrwalone przekazy, tworzy „alternatywne narracje” (alternative narratives), podważając ideę wersji ostatecznej. Przyjęte przez niego sposoby działania, zdaniem Nicolasa Bourriauda

zachęcają nas do rozważania globalnej kultury jako zestawu narzędzi, przestrzeni otwartej, a nie jednoznacznej narracji (...). Zamiast bicia pokłonów dziełom przeszłości, możemy je wykorzystać ${ }^{37}$.

Sztuka, jak przekonuje autor „Estetyki relacyjnej”, powołując się na przykłady analizowanych przez siebie twórców, „może być formą użycia świata, niekończącą się negocjacją różnych punktów widzenia" ${ }^{38}$. Francuski krytyk dochodzi do wniosku, że działalność współczesnych twórców w dużej mierze uskutecznia opisane przez autora „Wynaleźć codzienność” „sposoby kłusowania", opierając się na wykorzystaniu materiałów już istniejących i udostępnionych w cyfrowych bazach danych, przyczynia się do ostatecznej

\begin{abstract}
likwidacji tradycyjnego rozróżnienia na produkcję i konsumpcję, tworzenie i kopiowanie, ready mades i oryginał. Materiał, którym operują nie jest dłużej „początkowym". Nie jest dłużej kwestią wypracowania formy na podstawie surowego materiału, ale pracą $\mathrm{z}$ obiektami, funkcjonującymi $\mathrm{w}$ obiegu rynku kultury (...). Pojęcia oryginalności (będącej źródłem), a nawet kreacji (tworzenia czegoś z niczego) powoli zacierają się w nowym pejzażu kulturowym znaczonym podwójną figurą DJ-a i programisty, których zadaniem jest wybieranie obiektów i umieszczanie ich w nowych kontekstach ${ }^{39}$.
\end{abstract}

Kreślona przez Bourriaud historia apriopriacji w sztuce sięga korzeniami ready mades Duchampa, dla którego akt wyboru dzieła, a nie jego własnoręczne wykonanie, okazał się warunkiem wystarczającym do zaistnienia sztuki. Postprodukcja jest współczesną odmianą zapoczątkowanej przez niego gry artystycznej, polegającej na ścisłej relacji z bogactwem dotychczasowych źródeł:

W tym nowym kształcie kultury, którą można nazwać kulturą użycia (culture of use) czy kulturą aktywności (culture of activity) dzieło sztuki funkcjonuje jako tymczasowy terminal sieci połączonych ze sobą elementów, takich jak narracja, która rozciąga się, reinterpretując opowieść poprzedników ${ }^{40}$.

Zapoczątkowany przez Duchampa proces „użycia obiektów” (The Use of Objects) kontynuowali artyści pop artu (Andy Warhol, Cleas Oldenburg,

\footnotetext{
${ }^{37}$ Bourriaud, 2002a, s. 94.

${ }^{38}$ Ibidem, s. 94.

${ }^{39}$ Ibidem, s. 6.

${ }^{40}$ Ibidem, s. 19.
} 
James Rosenquist), nowego realizmu (Martial Raysse, Raymond Hains, Jacques Villeglé) czy twórcy z kręgu appropriation art (Sherrie Levine, Barbara Kruger, Jeff Koons). Ich działania stanowią, zdaniem Bourriaud, pierwszy etap rozwoju idei postprodukcji. Kolejny wyznacza oparta na remiksie twórczość lat 80. i 90., która wykorzystując demokratyzację dostępu do komputera, promuje kulturę DJ-a i związany z nią proces "użycia form” (The Use of Forms). Opisany przez niego proces użycia obiektów, form, w końcu sposób „użycia świata" (The Use of World) obrazuje zmiany w sposobie rozumienia współczesnej działalności twórczej, utożsamianej wielokrotnie z działalnością bricoleura, który z „przechwyconych” obiektów czy form komponuje własne dzieła. Współcześni artyści, jak sam zapewnia, programują i remiksują dostępny im materiał, wykorzystując zasoby cyfrowych baz danych otwartych na reprodukcję.

W innym przypadku kategoria archiwum zostaje wykorzystana przez artystów jako podstawowy budulec dzieła sztuki. Lev Manovich mówi w tym kontekście o sztuce baz danych (art of database), która jest rodzajem praktyki artystycznej opierającej się na wykorzystywaniu informacji (danych, baz danych) jako materii pracy ${ }^{41}$. Przykładem dobrze ilustrującym opisane zjawisko jest pionierski projekt „File Room” Antonio Muntadasa z 1994 roku, jedna z pierwszych prac wykorzystujących archiwizacyjny potencjał sieci. Dzieło, składające się ze strony internetowej i zaprezentowanej w chicagowskim Cultural Centre instalacji, przyjęło formę otwartej bazy danych, dokumentującej zjawisko cenzury w sztuce. Współtworzone przez odbiorców publiczne archiwum zawiera informacje dotyczące daty, miejsca, medium i powodów cenzurowania artystycznych działań. Podobną strategię organizacji dzieła zastosował także George Legrady w swojej pracy „Pockets Full of Memories” (2001), Golan Levin, Kamala Nigama i Johnatan Feinberg w projekcie „The Dumpster” (2006) czy Paolo Cirio i Alessandro Ludovico w pracy „Face to Facebook" (2011). Wspomniane wyżej projekty wpisują się w bogatą tradycję awangardowych działań opartych na praktykach archiwizacyjnych podejmowanych m.in. przez Marcela Duchampa w jego „Pudełku w walizce” (1938-40) i „Zielonym Pudełku” (1934-40), w walizkach tzw. „Fluxkit” (1965-1966) grupy Fluxus, czy działaniach grupy Art\&Language szczególnie w pracy "Index 1" (1972). Nowe media zintensyfikowały poszukiwania artystyczne w tym obszarze, wykorzystując nieznane możliwości technologiczne i prze-

${ }^{41}$ Ryszard Kluszczyński mówi w tym kontekście praktykach artystycznych realizujących strategię archiwum, które „oferują jako przestrzeń doświadczenia, zasoby informacyjne uporządkowane w przejrzystą strukturę bazy danych.” Zob. Kluszczyński 2010, s. 237. 
kraczając wcześniejsze ograniczenia. Victoria Vesna, dostrzegając tę wyraźną tendencję $\mathrm{w}$ ramach sztuki nowych mediów w redagowanej przez siebie książce „Database Aesthetics”, proklamowała niejako powstanie nowej dyscypliny badawczej, jaką jest estetyka bazodanowa. Jej zdaniem współcześni

\begin{abstract}
Artyści wykorzystujący internet jako medium są szczególnie zainteresowani tworzeniem nowego typu estetyki, która nie tylko dotyczy aspektów wizualnej reprezentacji, ale także niewidzialnych aspektów organizacji, wyszukiwania informacji i nawigacji wśród nich ${ }^{42}$.
\end{abstract}

Sztuka jako archiwum to także sposób funkcjonowania sztuki opartej na procesie, w tym sztuki medialnej, która istnieje poprzez różne wersje, warianty czy poszczególne realizacje. Hanna Barbara Hölling wprowadza ciekawe z tej perspektywy rozróżnienie na sztukę slow i fast opierające się na relacji dzieła sztuki do czasu:

W przeciwieństwie do tradycyjnych dzieł sztuki, takich jak malarstwo czy rzeźba, które podlegają entropii i rozpadowi, które można określić jako „sztuka slow” ze względu na tempo ich rozpadu/zaniku, performance, instalacja i dzieła sztuki cyfrowej mogą być sklasyfikowane jako rodzaj „sztuki fast”, ponieważ są zazwyczaj doświadczane tylko przez bardzo krótki okres czasu, zanim się skończą ${ }^{43}$.

Sztuka długo trwająca (slow art) doskonale wpisuje się w koncepcję klasycznego muzeum, rozumianego jako instytucja skupiająca się na gromadzeniu, prezentacji i ochronie materialnych obiektów sztuki. Sztuka krótko trwająca (fast art) stanowi dla niej nie lada wyzwanie, wymuszając potrzebę redefinicji praktyk wystawienniczych, kolekcjonerskich czy konserwatorskich podejmowanych $\mathrm{w}$ ramach instytucji. Na przykładzie twórczości artystów z kręgu Fluxus Hölling przybliża zaproponowane pojęcie „szybkiej sztuki”, która po zakończeniu domaga się uzupełnienia, wymuszając niejako odbiorczą potrzebę kolekcjonowania i zbierania tego, co po niej pozostało. Dzieła oparte na procesie, tj. performance, zdarzenia, wideo, instalacje, sztuka nowych mediów, trwając krótko, wytwarzają ogromną liczbę materiałów, dokumentacji (fotografia, film, tekst), śladów, które starają się zapobiec jej ulotności. W ten sposób dzieło sztuki staje się swoim własnym archiwum, „akumulacją śladów własnej trajektorii”" . Przywołując Martina Heideggera, można powiedzieć, że dzieło sztuki nie znika tak po prostu w świecie, ale raczej kreuje swój własny świat ${ }^{45}$.

\footnotetext{
${ }^{42}$ Vesna 2007, s. XIII.

${ }^{43}$ Hölling 2016a, s. 10.

${ }^{44}$ Hölling 2016c.

${ }^{45}$ Cyt za: ibidem.
} 
Zwrot archiwalny, wpisujący się w szerszy kontekst przemian współczesnych badań humanistycznych, zasadniczo wpłynął na praktykę artystyczną, która dodatkowo zmienia się pod wpływem nieznanych wcześniej możliwości oferowanych przez technologię. Nowe media zredefiniowały sposób rozumienia samej kategorii archiwum, określając nowe sposoby jego funkcjonowania i wykorzystywania w kontekście sztuki. Sztuka baz danych jest nowym zjawiskiem wykorzystującym komputerowe możliwości archiwizowania, magazynowania i kontekstualizowania danych, które wpływają na współczesną praktykę artystyczną. Sztuka staje się archiwum zarówno w kontekście organizacji dzieła, jak również jego sposobu funkcjonowania w szerszym obiegu sztuki. Zmiany w obrębie samej kategorii archiwum ujawniają jednocześnie jego duży potencjał krytyczny, odkrywając to, co dotąd ukryte, niedostępne szerszemu kręgowi odbiorców. To, co dotąd przemilczane i nieobecne w szerszym dyskursie sztuki.

\section{BETWEEN THE ARCHIVE AND THE DATABASE - THE EXPERIENCE OF NEW MEDIA ART}

\section{Summary}

Gathering, collecting, and organizing material is a natural human need, deriving in part from nostalgia for the past as well as resulting from the desire to place oneself in the sequence of history, in a relationship to what was and what future generations will partake in. In this context, Derrida speaks of „archive fever” which is both a need to organize the past, and an inner impulse that defines human existence. The contemporary challenge consists in redefining one's approach to cultural archives in the age of networked media. The paper addresses the issue of digital database which amass media artworks, discusses collecting, protection and archiving of new media art. The author takes a look at Polish institutional practice, specifically the activities of the WRO Art Center, which since 1989 has been engaged in documenting, digitizing, describing and protecting new media art, in order to reflect what role it plays in constructing alternative histories of contemporary art.

\section{Bibliografia}

Bourriaud N. 2002, Postproduction: Culture as Screenplay: How Art Reprograms the World, New York.

Bourriaud N. 2002, Relational Aesthetics, Dijon.

Celiński P. 2013, Postmedia. Cyfrowy kod i bazy danych, Lublin. 
Derrida J. 2006, Archive Fever, [w:] Ch. Merewether (red.), The Archive. Documents of Contemporary Art, London.

Ernst W. 2015, Stirring in the Archive, New York-London.

Foster H. 2004, An Archival Impulse, „October”, 110.

Godfrey M. 2007, Artist as Historian, „October”, 120.

Hölling H.B. 2016a, Sztuka i proces: kontynuacja, względny czas trwania i archiwum Fluxus, [w:] I. Szmelter (red.), Sztuka w procesie/proces w sztuce. Ku nowej filozofii ochrony dziedzictwa kultury, Warszawa.

Hölling H.B. 2016b, The Archiwal Turn: Toward New Ways of Conceptualising Changeable Artworks [online]. Hanna Hölling [dostęp: 2016-12-31]. Dostępny w Internecie: <http:// www.hannahoelling.com/wp-content/uploads/2016/09/The_Archival_Turn.pdf >.

Hölling H.B. 2016c, Lost to Museums? Changing Media, Their Worlds, and Performance, Museum History Journal.

Hölling H.B. 2017, Paik's Virtual Archive: Time, Change, and Materiality in Media Art, Berkeley.

Kluszczyński R. 2010, Sztuka interaktywna. Od dzieła-instrumentu do interaktywnego spektaklu, Warszawa.

Krajewski P. 2016, Aktywne archiwum sztuki, Mocak. Forum, 1.

Leśniak A. 2011, Gorączka archiwum w sztuce współczesnej. Symptomy choroby i propozycja terapii, Kultura współczesna, 4 (70).

Lovejoy M. 2011, Introduction, [w:] M. Lovejoy, Ch. Paul, V. Vesna (red.), Context Providers: Conditions of Meaning in Media Arts, Chicago.

Manovich L. 2006, Język nowych mediów, Warszawa.

Merewether Ch. 2006, Introduction, [w:] Ch. Merewether (red.), The Archive. Documents of Contemporary Art, Cambridge MA, London.

Nader L. 2019, O czym zapominają archiwa? Pamięć i historie [online]. Z archiwum KwieKulik [dostęp: 2019-03-30]. Dostępny w Internecie: <http://kulikzofia.pl/archiwum/luiza-nadero-czym-zapominaja-archiwa-pamiec-i-historie-z-archiwum-kwiekulik/>.

O WRO 2018 [online]. WRO Center [dostęp: 2018-12-04]. Dostępny w Internecie: <http:// wrocenter.pl/pl/o-wro/>.

Sterling B. 2017b, Digital Decay [online]. Medium [dostęp: 2017-12-04]. Dostępny w Internecie: <https://medium.com/@bruces/digital-decay-2001-b0db0ca4be3c >.

Streling B. 2017a, The DEAD MEDIA Project. A Modest Proposal and a Public Appeal [online]. Dead media [dostęp: 2017-12-04]. Dostępny w Internecie: <http://www.deadmedia. org/modest-proposal.html>.

The Art. Od Participation 1950 to now 2008, R. Frieling, B. Groys, R. Atkins, L. Manovich (red.), San Francisco.

Vesna V. 2007, Introduction, [w:] Database Aesthetics. Art in the Age of Information Overflow, V. Vesna (red.), London.

Weinbren G. 2007, Ocean, Database, Recut, [w:] V. Vesna (red.), Database Aesthetics. Art in the Age of Information Overflow, London.

Wysocka E. 2013, Wirtualne ciało sztuki. Ochrona i udostępnianie dzieł audiowizualnych, Warszawa.

Zawojski P. 2010, Cyberkultura. Syntopia sztuki, nauki i technologii, Warszawa.

Zwroty badawcze w humanistyce konteksty poznawcze, kulturowe i społeczno-instytucjonalne 2010, J. Kowalewski, W. Piasek (red.), Olsztyn. 